\title{
Humberto López Cruz: Tetrapalabra. Cuatro ensayos sobre letras cubanas. Valencia: Aduana Vieja Editorial, 2020.
}

Este libro, publicado por Aduana Vieja Editorial en Valencia, cautiva la curiosidad con una muestra inesperada del poder evocativo de las palabras ya con la firma de su prólogo, fechado en Winter Springs, el otoño de 2019. Las tres estaciones del año, de forma bilingüe — tan adecuada si pensamos en el último capítulo del libro - resaltan la única ausencia, la del verano, cuyo esplendor tanto nos llegó a faltar en el difícil 2020, año de edición del libro. Esta evocación resulta de nuevo sugerente si tomamos en consideración la estructura del libro: cuatro capítulos sobre cuatro figuras destacadas de la literatura cubana: Gastón Baquero, Reinaldo Arenas, Leonardo Padura y Roberto G. Fernández. Con ello, se forma una suerte de Quattro Stagioni de ensayos literarios.

Este mismo hecho hace que las obras tratadas sean de carácter heterogéneo, por tanto, no todas pertenecientes al género de la narrativa breve; habrá que perdonar, sin embargo, la lenidad de tal criterio en la presente reseña: su aplicación estricta conllevaría que, por esta misma diversidad de los temas y las categorías, el libro se viera injustamente excluido de las revistas temáticas. Aquí, más que perdernos su valor por el rigor del criterio, se prefiere la flexibilidad para abrirnos a su apreciación.

El tomo es, según declara el prólogo, "una recopilación de ponencias y publicaciones", aunque con las necesarias "adiciones y actualizaciones". Por tanto, la misma introducción confiesa un "aura de redundancia" en "fragmentos fundamentales que aplican a más de un punto discutido" (13). Sin embargo, se puede argumentar que, como compendio de la trayectoria investigativa del autor, tales repeticiones adquieren cierto valor enfático: en una obra de este carácter, las repeticiones pueden muy bien servir los propósitos de establecer los acentos y de ofrecer una síntesis de la visión guiada por esa "inquietud por estas letras" (9), recalcada varias veces en la parte inicial del tomo.

No está de más recalcar este valor sintético del libro, porque parece que — por modestia u otra causa - está más presente de lo que el mismo autor resalta. La estructura formal también sugiere separación: cada capítulo dispone de su bibliografía aparte — detallada e indicada con cuidado para que el lector pueda seguir profundizando en el tema que más le interese-, situada al final de cada capítulo (detalle útil para la búsqueda especificada, pero un poco desconcertante a primera vista, al faltar aviso explícito de ello), y no se añade una reflexión final posterior a los cuatro capítulos. Sin embargo, se puede divisar muy bien un arco más amplio en estos textos investigativos: de una manera mediada, cada uno de los capítulos reflexiona - de acuerdo con los ejes de interés en cada autor analizado - sobre una faceta distinta del cubanismo, cada una de ellas sugestiva y notable para ensanchar los conocimientos respectivos.

El primer capítulo introduce la cuestión de la presencia africana en la cultura cubana, muy claramente expuesta ya desde su título: "La ineludible africanidad en la palabra de Gastón Baquero: una lectura que aspira a ser transatlántica" (15-39), haciendo mención tanto de la ensayística de Baquero como de su poesía; el apartado ofrece, además, una reflexión sobre los estudios transatlánticos. Destaca, en este marco, cómo el cruce España-América Latina ha venido siendo el eje de tales estudios y subraya la necesidad de dar mayor peso a la dirección africana para lograr la perspectiva de un triángulo intercontinental. Ello hace que se 
amplíe la constatación superficial sobre el "encuentro de dos mundos" y, para ello, no hay presencia más patente que la africana en Cuba. Para tales reflexiones presenta una intersección ventajosa la obra poética, ensayística y periodística de Gastón Baquero, con su reivindicación de lo africano como elemento emancipado en la formación de la identidad cubana $\mathrm{y}$, en un plano más global, de aquella latinoamericana, forjando un imaginario inclusivo. En este sentido destaca el estudioso la prosa de Baquero como una llamada al diálogo y una válida base para el resto de los estudios.

La segunda unidad del libro se titula "Subversión apocalíptica en el discurso histórico de El color del verano, de Reinaldo Arenas: interpolación avalada por su autobiografía" (4190), y persiste en abarcar una variedad genérica al hacer alusión a la poesía de Arenas, además de analizar, principalmente, su obra en prosa. Si la parte referente a Baquero insiste en el elemento africano ignorado como colectivo — una inquietud social—, se acentúa la opresión de un individuo y la inquietud psíquica a propósito de Arenas, vejado por el régimen de Fidel Castro (aunque queda claro que no se ha de ignorar la faceta social de su humillación como homosexual). El viaje, en su caso, es un exilio forzado por tales circunstancias, voluntario solo en cuanto medio de preservar su propia libertad, en la que su identidad sexual constituía otro territorio recluido. El análisis de López Cruz evidencia la plasmación narrativa de dicha preservación en la multiplicidad de las identidades narrativas y narratoriales, y apunta en ello a una rebelión literaria contra un sistema de intolerancia oficial, de manera subversiva y en correspondencia con la dualidad de los discursos privado y público (vivencias de la miseria - elogio oficial del progreso). Se exhibe, en este eje de polaridad, el concepto de país y contrapaís (valores, hermosura, vitalidad-poder opresivo). El investigador llama la atención al nexo entre Arenas y Virgilio Piñera - pupilo y maestro-, que se configura también mediante la aparición de Piñera como personaje de El color de verano, formando un vínculo intertextual lleno de resonancias y afinidades. Estas adquieren especial interés en la relación que el estudio establece entre las obras y la autobiografía de Arenas, medios ambos de expresar sus convicciones - marcadas por un enfurecimiento perenne - sobre la visión del futuro de Cuba, de la demolición del individuo y de la nación, visión apocalíptica, guiado por la cual se lanzó al suicidio en un acto supremo de protesta y condena, en el paso consumado de su desafío al poder.

Si en el segundo apartado del libro se habla de la necesidad de exiliarse del país, el tercer capítulo versa sobre la otra cara de la moneda: de la inercia de quedarse y de sus consecuencias. En esta sección, titulada "La exaltación gastronómica de Leonardo Padura: tras la pista de sus festines pantagruélicos” (91-111), el análisis centra su atención en la tetralogía de Las cuatro estaciones (1991-1998) — otra afinidad con la estructura tipo Quattro Stagioni del libro-, protagonizada por el detective Mario Conde. Expone que esta saga ha conllevado la renovación estética del género policial en Cuba, al ser sus personajes más que fichas en un puzzle: auténticos signos de una ciudad y una civilización atascadas entre el descontento y la promesa. Se presta atención particular a la novela Pasado perfecto (1991), cuya acción se desarrolla en una casi-contemporaneidad: tiene lugar en 1989, año emblemático por la caída de la Unión Soviética y del Muro de Berlín, pero también en una escala local, por el proceso al general Ochoa. López Cruz observa cómo sirve esta óptica para examinar, juzgar y narrar la sociedad de la época. A todo ello, la presencia culinaria aporta una visión folclórica, en un intento de afianzar el patrimonio cultural cubano por medio de la 
gastronomía. Este mismo aspecto tampoco se ausenta de contenidos sociales, al plasmarse en contraste con las libretas de racionamiento alimenticio presentes en Cuba desde los años 60, una época en la que "nadie se ha muerto de hambre [...] pero donde casi nadie ha comido lo que quiere" (96). Por tanto, esos festines no ofrecen verosimilitud en el contexto: es esta la faceta de la obra de Padura que López Cruz investiga en detalle, centrándose en el personaje de Josefina y su evolución entre delincuencia y resistencia.

El cuarto y último capítulo del libro es el que tiene que ver más directamente con la narrativa breve: "Inclusión narrativa, confusión anticipada: aspectos significativos de la obra de Roberto G. Fernández” (113-161). Hijo del exilio, Fernández también vive esa condición, tal como Arenas pero, al contrario, él ya escribe sobre la vida en la comunidad cubanoamericana: si el libro ha empezado con lo que llegó a Cuba a través de las raíces africanas, el arco — poco enfatizado pero no por ello menos enfático - se cierra con lo que ha dejado el país: su cultura -o su dilución - en un nuevo contexto geográfico y lingüístico. La imaginería de Fernández se conecta también con el apartado anterior cuando López Cruz destaca la sátira y las hipérboles (recuérdese lo "pantagruélico" en Padura) como herramientas clave del autor sobre el cubano en suelo norteamericano. Subraya, asimismo, la constancia del estilo narrativo de Fernández, en contraste con la variación en los géneros literarios que cultiva, caracterizado también por sus juegos con el texto y con el lector, de carácter dialogante, en conspiración entre ellos y, por su narrativa carnavalesca, interpolada con la presencia lingüística del Miami hispano en ciertos estereotipos costumbristas, en la que la confusión textual es un agente recurrente. El investigador hace referencia especial a Jorge Febles y a Mary L. Seale, estudiosos destacados de Fernández.

Para los interesados en la narrativa breve, este capítulo presenta, sin duda, una atracción especial, visto que analiza géneros que se permean en hibridez. López Cruz destaca las microficciones, que aparecen en un contexto insólito, como materia de novelas: de hecho, estas últimas consisten, en la obra de Fernández, en una variedad de historias dispersas con una unidad argumental orientada a lograr la cohesión necesaria. Por tanto, se analiza aquí el contacto entre narrativa breve y novela. La hibridez genérica se empareja con aquella lingüística: es notable el recuento de historias recurrentes o republicadas - con mención de sus diferencias inherentes - entre Raining Backwards (1988), En la Ocho y la Doce (2001) y Entre dos aguas (2006), las tres en castellano, y Holy Radishes! (1995), escrita en inglés. La coexistencia fluida e híbrida de límites geográficos, lingüísticos (literatura hispánicaliteratura anglosajona) y genéricos (ficción-microficción) es la que genera el interés especial de este estudio.

Tratándose de microficciones, López Cruz incluye en este apartado criterios de la teoría del género, aceptando los preceptos de Jerome Stern (límite de extensión: 250-300 palabras) y su recordatorio a los antecedentes genéricos (los trick form con una vuelta final inesperada en las revistas populares de las épocas anteriores a la televisión), aduciendo las observaciones de Fernando Valls (los otros géneros narrativos no permiten mostrar con tanta intensidad y énfasis conductas, sentimientos o estados de ánimo) y destacando también las observaciones de Ottmar Ette sobre este "cuarto género narrativo", referidas a su aumento en sutileza y complejidad en la construcción de antologías y de tomos. En este sentido, las obras de Fernández constituirían una cumbre: en cuanto a La vida es un special (1981) — “serie de viñetas", según se recoge la definición de Carolina Hospital— se destaca su posible lectura, a 
primera vista, como una sucesión de cuentos, entendibles por separado, mientras que la recurrencia de personajes entre distintos conjuntos de microficciones (se menciona que Raining Backwards funciona como punto de origen de las obras En la ocho y la doce y Entre dos aguas) favorece su lectura como novela que apela a la función unificadora del lector.

Quizá sea justamente el análisis del personaje de Mirta — de Raining Backwards — la parte de alcance más universal de los estudios aquí recogidos: el investigador analiza cómo crea Mirta una realidad virtual, de manera no desvelada, en una microficción dentro de la novela y cómo forja sus versiones de los ¿hechos? en otros momentos. Tal procedimiento sirve, según constata López Cruz, como desmontaje de los mitos de la comunidad cubana del postexilio: los recuerdos se convierten en fantasías, los intentos de recordar significan un apartarse de la realidad, y todo ello lleva a la reinvención del pasado; pero ya no a la (re)elaboración de un pasado existente sino a la (re)estructuración de uno inexistente, con lo cual se establece una dependencia del mito para la supervivencia social del individuo. La incapacidad de adaptarse al presente hace que se produzca un intento de vivir una vida añorada y no consumada. Con este tramo del análisis, el autor logra tantear algo que apunta incluso más allá de las diversas facetas de los desplazamientos, y nos lleva a reflexionar sobre el papel universal de la ficción como facultad humana.

El libro de Humberto López Cruz se muestra abierto hacia el futuro bajo varios aspectos: se destaca, en el prólogo, su abstención de citar algún que otro nombre consagrado para "abrir un espacio crítico a nuevas voces" y "hacia proposiciones que pueden seguir debatiéndose", y también se augura, para un futuro no muy lejano, la presentación de otros análisis sobre otras figuras destacadas de las letras cubanas. Y, si es condición del lector no haber leído algunos de los autores analizados, es, sin duda, logro del autor haberlo dejado con ganas de remediar la falta.

Ádám András Kürthy Universidad Eötvös Loránd kurthy.adam.a@gmail.com

DOI: https://doi.org/10.24029/1ejana.2020.14.1674

Recibido: el 31 de agosto de 2020

Aceptado: el 26 de octubre de 2020

Publicado: el 26 de febrero de 2021

(C) Ádám András Kürthy

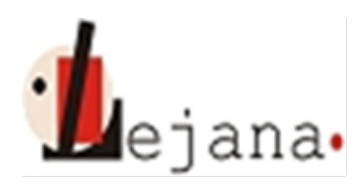

http://ojs.elte.hu/index.php/lejana

Universidad Eötvös Loránd, Departamento de Español, 1088 Budapest, Múzeum krt. 4/C 